Fourth International Conference on Sustainable Construction Materials and Technologies http://www.claisse.info/Proceedings.htm

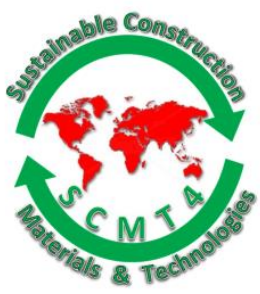

SCMT4

Las Vegas, USA, August 7-11, 2016

\title{
Improvement of Mechanical Performance in Different Concrete Applications through Use of Steel Fibers
}

\author{
Eray Baran 1 , H. Cenan Mertol ${ }^{2 a}$, and Tolga Akis ${ }^{2 b}$ \\ ${ }^{1}$ Middle East Technical University, Civil Eng. Dept., Ankara, Turkey. Email: erayb@metu.edu.tr \\ ${ }^{2}$ Atilim University, Civil Eng. Dept., Ankara, Turkey. \\ ${ }^{2 a}$ E-mail: <cenan.mertol@atilim.edu.tr>, ${ }^{2 b}$ E-mail: $\langle$ tolga.akis@atilim.edu.tr>.
}

\begin{abstract}
The use of steel fibers improves the brittle characteristics of concrete and provides superior mechanical performance compared to the conventional concrete. Remarkable increase in tensile strength and flexural toughness is obtained when steel fibers are used in conventional concrete, mainly due to the crack arrest effect of these fibers. The use of waste materials, such as scrap tires as a source of steel fibers, as well as the resulting increase in service life and the savings in the life cycle cost make the steel fiber reinforced concrete (SFRC) a sustainable construction material. From this perspective, SFRC offers a strong potential for a more sustainable and more economical alternative to conventional concrete. This paper presents examples of how the addition of steel fibers improves the mechanical performance in two different concrete applications: (1) bond behavior of prestressing strands and (2) flexural behavior of reinforced concrete beams. The first part of the study aimed at investigating the variation in bonding mechanism of prestressing strands when used in plain concrete and in SFRC. Pullout tests were conducted on $12.7 \mathrm{~mm}$ diameter prestressing strands embedded in SFRC blocks with four different fiber concentrations. This way, the applicability of the available transfer length and development length formulas for prestressing strands embedded in SFRC was investigated. In the second part of the study, flexural behavior of SFRC beams with various levels of flexural reinforcement ratio was studied. The aim was to identify the influence of steel fibers on the mechanical response of lightly and relatively heavily reinforced SFRC beams. The response of SFRC beams and the companion plain concrete beams were evaluated based on the moment capacity, deformation capacity, and service stiffness.
\end{abstract}

\section{INTRODUCTION}

Fiber reinforced concrete offers various improvements in mechanical properties of plain concrete. The degree of improvements usually depends on the fiber material and shape, as well as the fiber content in the mixture. Fibers used in concrete are usually made of steel, glass, plastic, or natural materials. Steel fiber reinforced concrete (SFRC) proved to be a useful application in conventional reinforced concrete and prestressed concrete beams, enhancing the flexural and shear resistance [Elliot et al. 2002; Padmarajaiah and Ramaswamy 2004; Qian and Patnaikuni 1999; Abdul-Ahad and Aziz 1999; Ashour et al. 2000; Dancygier and Savir 2006; Altun et al. 2007; Olivito and Zucarello 2010; Gustavo et al. 2010]. Based on 
the results of load tests on concrete beams reinforced with a combination of steel bars and steel fibers, Qian and Patnaikuni reported improvement in stiffness and post-peak load resisting ability of beams with no significant effect on the number and length of cracks [Qian and Patnaikuni 1999]. Altun et al. reported that reinforced concrete beams with steel fibers had more favorable behavior in terms of the initiation, size, and propagation of flexural cracks as compared to the beams with conventional concrete [Altun et al. 2007]. Abdul-Ahad and Aziz tested T-shaped reinforced concrete beams with various amounts of steel fibers and concluded that the addition of steel fibers resulted in an increase in the ultimate load capacity of both underreinforced and over-reinforced beams [Abdul-Ahad and Aziz 1999]. Dancygier and Savir investigated the behavior of concrete beams with steel fibers and with minimum amount of steel reinforcement [Dancygier and Savir 2006]. The experimental results indicated that the addition of fibers reduced the ductility of lightly reinforced beams. Based on this observation, an increase in minimum flexural reinforcement ratio was proposed for concrete beams with steel fibers in order to achieve a sufficient level of ductility.

Because the bonding between steel reinforcement and the surrounding concrete is crucial for successful performance of prestressed concrete and conventional reinforced concrete members, bond behavior of prestressing strands have been studied by several researchers. In majority of these studies, pull-out tests were performed on untensioned prestressing strands embedded in concrete blocks. This type of testing has been used to evaluate the bond performance of the strands since the procedure is fairly simple [Logan 1996]. Rose and Russell performed pull-out tests on both tensioned and untensioned $12.7 \mathrm{~mm}$ diameter strands to investigate their bond performance [Rose and Russel 1997]. It was reported that the pull-out tests on tensioned strands are difficult to perform and produce inconsistent results regarding the bond strength of strands. Girgis and Tuan performed pull-out tests on $15.2 \mathrm{~mm}$ diameter untensioned prestressing strands embedded in small prisms and large blocks made of self-consolidating concrete [Girgis and Tuan 2005]. Their results indicated that testing the strands in large concrete blocks resulted in approximately $20 \%$ higher bond strength than testing them in small prisms. Chao et al. investigated the bond behavior of $12.7 \mathrm{~mm}$ diameter untensioned strands embedded in small concrete prisms reinforced with various types of fibers [Chao et al. 2006]. Fibers added to concrete matrix with $1 \%$ volume fraction were found to improve the pull-out behavior of strands by limiting the crack width in concrete prisms.

Despite the potential use of SFRC in prestressed concrete structural members there is limited information regarding the bond behavior of prestressing strands. The first part of the study presented in this article investigates the bond behavior of $12.7 \mathrm{~mm}$ diameter seven-wire prestressing strands in concrete mixes with different steel fiber concentrations. In the second part of the study, flexural behavior of SFRC beams with various levels of flexural reinforcement ratio was studied. The aim was to identify the difference in mechanisms through which the existence of steel fibers improves the flexural response of lightly and relatively heavily reinforced concrete beams.

\section{EXPERIMENTAL STUDIES}

The fibers used in the experimental program were Dramix ZP-305 hooked end steel fibers that are $30 \mathrm{~mm}$ long with a diameter of $0.55 \mathrm{~mm}$ as shown in Figure 1. The fibers had a manufacturer specified minimum tensile strength of $1100 \mathrm{MPa}$ and they are reported to conform ASTM A820 Standards. Prior to the strand pull-out and flexural beam tests, materials tests were conducted on concrete cylinders and modulus of rupture beams in order to characterize the mechanical properties of the SFRC. The material tests included compressive strength tests, split tensile strength tests, and flexural tensile strength tests. The tests on SFRC were repeated for four different fiber contents: $15 \mathrm{~kg} / \mathrm{m}^{3}, 30 \mathrm{~kg} / \mathrm{m}^{3}, 45 \mathrm{~kg} / \mathrm{m}^{3}$, and $60 \mathrm{~kg} / \mathrm{m}^{3}$ (corresponding volumetric ratios of fibers are approximately $0.2 \%, 0.4 \%, 0.6 \%$, and $0.8 \%$ ). Control specimens were also tested with plain concrete with no steel fibers. The concrete mix had a target 28-day compressive strength of $40 \mathrm{MPa}$. Figure 2 shows the test setup used for flexural tensile strength tests, as well as the extent of deformation occurred on a specimen. 


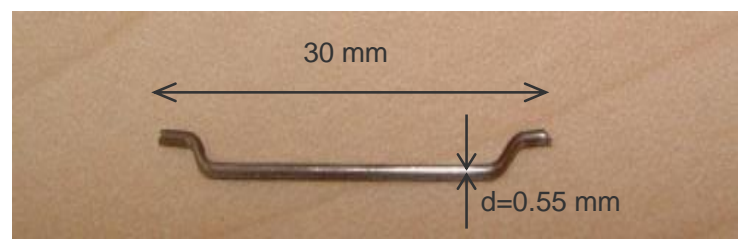

Figure 1. Fiber geometry used in the study

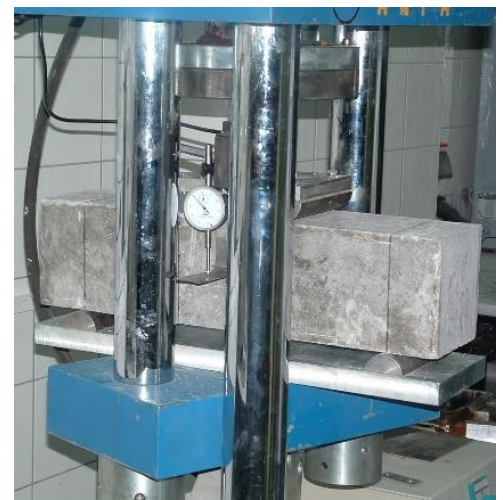

(a)

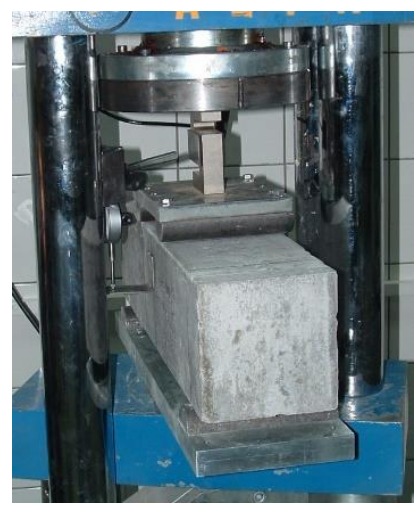

(b)

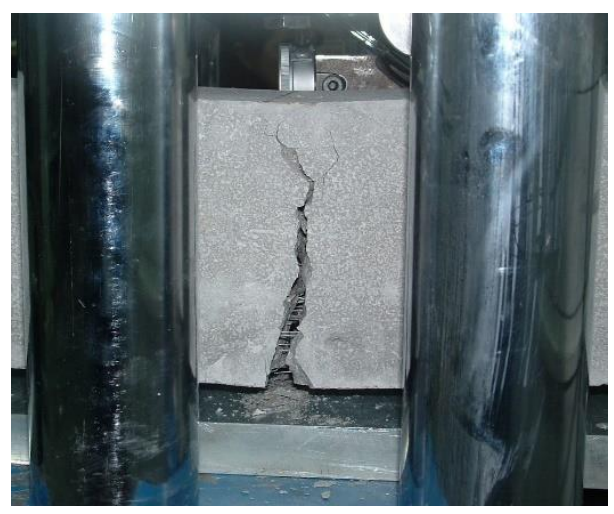

(c)

\section{Figure 2. Flexural Beam Test Setup: (a) Side View; (b) End View; (c) Flexural Crack Opening}

Results from the material tests are presented in Table 1. The strength values shown in the table are the average of results from three repeated tests. The addition of steel fibers resulted in a small decrease in the measured concrete compressive strength. The largest decrease in compressive strength was $8.2 \%$. A similar decrease in compressive strength with the addition of steel fibers was previously observed by other researchers and the reason for such decrease could be attributed to insufficient compaction due to the presence of steel fibers in the mix. The addition of steel fibers caused an increase in both the split tensile and the flexural tensile strengths. This was an expected result, because it is well known that the steel fibers are effective in arresting the cracks in concrete and therefore delaying the failure caused by cracking. This way, the load that the concrete is able to resist continues to increase following the initiation of cracking. The percent difference in split tensile strength increased with the fiber content, while the percent difference in flexural tensile strength decreased with the fiber content.

Addition of steel fibers in concrete results in significant improvements in its flexural response. The parameter called "flexural toughness" is widely used to characterize the flexural performance of SFRC. Flexural toughness is the area under the load-deflection curve obtained from a flexural beam test up to a specific deflection value. The flexural toughness of SFRC determined this way is a measure of the energy absorption capacity of the material. Three major flexural toughness parameters as specified by ASTM C1018-97 [ASTM 1997] standards were used to assess the flexural response of beam specimens tested in this study. These parameters are the first crack toughness, the toughness index $I_{5}$, and the toughness index $I_{10}$. The first crack toughness is related with the pre-cracking region of the load-deflection curve, while the other two are a measure of the energy absorption capability in the post-cracking region. The toughness values tabulated in Table 2 indicate that toughness indices $I_{5}$ and $I_{10}$ generally increase with an increase in fiber content. 
Table 1. Compressive and Tensile Strength Results

\begin{tabular}{|c|c|c|c|c|c|c|c|}
\hline \multirow[b]{2}{*}{ Fiber type } & \multirow{2}{*}{$\begin{array}{l}\text { Fiber } \\
\text { content }\end{array}$} & \multicolumn{2}{|c|}{$\begin{array}{l}\text { Compressive } \\
\text { strength }\end{array}$} & \multicolumn{2}{|c|}{ Split tensile strength } & \multicolumn{2}{|c|}{$\begin{array}{l}\text { Flexural tensile } \\
\text { strength }\end{array}$} \\
\hline & & $\begin{array}{c}\text { Measured } \\
\text { strength } \\
\text { MPa }\end{array}$ & $\begin{array}{c}\mathrm{COV} \\
\%\end{array}$ & $\begin{array}{c}\text { Measured } \\
\text { strength } \\
\text { MPa }\end{array}$ & $\underset{\%}{\mathrm{COV}}$ & $\begin{array}{c}\text { Measured } \\
\text { strength } \\
\text { MPa }\end{array}$ & $\begin{array}{c}\mathrm{COV} \\
\%\end{array}$ \\
\hline No fiber & $\mathrm{n} / \mathrm{a}$ & 45.2 & 1 & 3.4 & 7 & 4.3 & 2 \\
\hline \multirow{4}{*}{ ZP-305 } & $15 \mathrm{~kg} / \mathrm{m}^{3}$ & 45.3 & 3 & 3.6 & 8 & 5.5 & 4 \\
\hline & $30 \mathrm{~kg} / \mathrm{m}^{3}$ & 42.5 & 3 & 3.8 & 4 & 5.0 & 7 \\
\hline & $45 \mathrm{~kg} / \mathrm{m}^{3}$ & 41.5 & 3 & 4.0 & 3 & 4.8 & 1 \\
\hline & $60 \mathrm{~kg} / \mathrm{m}^{3}$ & 43.5 & 3 & 4.0 & 6 & 4.6 & 10 \\
\hline
\end{tabular}

Table 2. Comparison of Toughness Indices

\begin{tabular}{|c|c||c|c|c|}
\hline $\begin{array}{c}\text { Fiber } \\
\text { type }\end{array}$ & $\begin{array}{c}\text { Fiber } \\
\text { content }\end{array}$ & $\begin{array}{c}\text { First crack } \\
\text { toughness } \\
\text { kN-mm }\end{array}$ & $\begin{array}{c}\text { Toughness } \\
\text { index I5 }\end{array}$ & $\begin{array}{c}\text { Toughness } \\
\text { index I }\end{array}$ \\
\hline \hline No fiber & $\mathrm{n} / \mathrm{a}$ & 11.2 & $\mathrm{n} / \mathrm{a}$ & $\mathrm{n} / \mathrm{a}$ \\
\hline \hline \multirow{3}{*}{ ZP-305 } & $15 \mathrm{~kg} / \mathrm{m}^{3}$ & 16.2 & 3.2 & 7.8 \\
\cline { 2 - 5 } & $30 \mathrm{~kg} / \mathrm{m}^{3}$ & 15.0 & 4.5 & 8.0 \\
\cline { 2 - 5 } & $45 \mathrm{~kg} / \mathrm{m}^{3}$ & 12.9 & 5.5 & 12.4 \\
\cline { 2 - 5 } & $60 \mathrm{~kg} / \mathrm{m}^{3}$ & 13.2 & 5.5 & 13.9 \\
\hline
\end{tabular}

The plain concrete specimens failed immediately after the formation of cracking with no further load carrying capability. For the SFRC specimens, even though the initiation of cracking caused a drop in the load resisted by the specimen and a reduction in the flexural stiffness, a stable behavior was exhibited with a significant level of load carrying capability in the post-cracking region. In fact, for most of the SFRC specimens, the maximum load reached in the post-cracking region was much larger than the load at first cracking. Ability of fibers to transfer loads may diminish in two ways: (1) the fibers may pull-out of concrete, or (2) the fibers may fracture if their anchorage to the concrete is strong enough. Pulling-out of individual fibers was observed during the flexural toughness tests. Following the pull-out of each individual fiber, the load is redistributed among other fibers that have not been pulled-out. This behavior continues as long as there are fibers available crossing the major crack.

Strand Pull-Out Tests. The most fundamental method of determining the bond characteristics of prestressing strands is through pull-out testing of untensioned strand pieces embedded in concrete. With this type of test, there are two major mechanisms through which the externally-applied pull-out load is resisted by the specimens. These are friction and mechanical bond between the strands and the surrounding concrete. Both of these load-resisting mechanisms diminish when the internal cracks in concrete reach a sufficient width around the strand location. In the cases that large cracking or splitting of the concrete is expected, the ability of SFRC to control the crack growth inside the concrete would delay or completely prevent the pull-out load resisting mechanisms to diminish thus enhance the bond characteristics. In this 
study, strand pull-out tests were conducted on $12.7 \mathrm{~mm}$ diameter seven-wire untensioned strand pieces embedded in SFRC blocks. The strand pull-out tests on SFRC were repeated for four different fiber contents: $15 \mathrm{~kg} / \mathrm{m}^{3}, 30 \mathrm{~kg} / \mathrm{m}^{3}, 45 \mathrm{~kg} / \mathrm{m}^{3}$, and $60 \mathrm{~kg} / \mathrm{m}^{3}$. Control specimens were also tested with plain concrete with no steel fibers.

A total of five pull-out test blocks, each containing six embedded strands, were cast for each fiber content. Dimensions of each concrete block were $700 \times 500 \times 200 \mathrm{~mm}$ and six strand pieces were embedded for the entire $200 \mathrm{~mm}$ concrete depth. Location of the strand pieces inside the concrete blocks is shown in Figure 3. Additional steel reinforcement was not used in order to avoid any effects on the pull-out behavior of the specimens. The strand pieces used in the study were obtained from a local prestressed concrete producer and reported to have a nominal tensile strength of $1860 \mathrm{MPa}$.
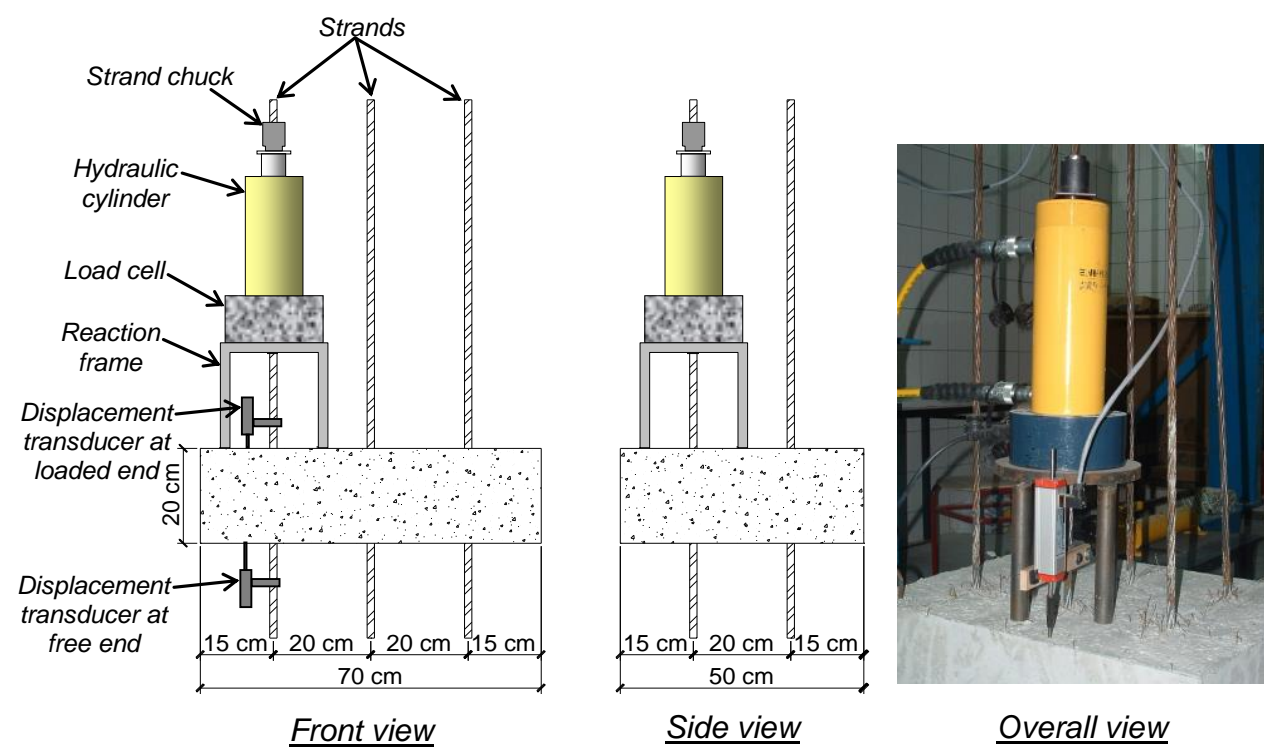

Figure 3. Details of Pull-Out Test Specimens and Test Setup

As shown in Figure 3, a center-hole hydraulic cylinder was used to pull out the strand pieces. The applied load was measured with a center-hole load cell placed between the hydraulic cylinder and the reaction frame. Slip values at the loaded end and free end of the strand pieces were electronically measured by a pair of displacement transducers, which were attached to the strands with the help of steel clamps. An incrementally-increasing displacement loading was applied to the specimens.

Results of Strand Pull-Out Tests. The cracking on concrete blocks was limited to the radial cracks localized near the strand location at the top surface of the blocks, for both the plain concrete and SFRC specimens. Pull-out load versus free-end slip behavior of all specimens are presented in Figure 4. The plots include results from six specimens tested for each fiber content. As evident in these figures, the overall shape of the pull-out load versus slip plot was not affected by the fiber content.

With the type of pull-out test used in this study, there are two distinct mechanisms through which the externally-applied pull-out load is resisted by the specimens. These are friction and mechanical bond between the strands and the surrounding concrete. As a result of the helical pattern of the outer wires, a seven-wire strand tends to rotate when subjected to pull-out loads. Consequently, the strands are pulled out of the concrete following a helical path, and frictional resistance occurs during this action. Mechanical bond, on the other hand, occurs when there is a restraint against free rotation of strands during the pull-out tests. In this case, the strands would not be able to follow exactly the helical path that was generated when 
the concrete was first cast around the strands. The resistance against pull-out provided by the friction and mechanical bond mechanisms depends on the level of confinement provided at the strand-concrete interface. As a result, the ability of a strand to resist pull-out diminishes when cracks in concrete near the strand location reach to a sufficient width. In this case, the load versus strand slip plot of the pull-out specimen is expected to drop rapidly. None of the specimens, however, tested in the present study showed such a rapid drop in pull-out load. The pull-out load resisted by specimens increased gradually with the strand slip up to free-end slip values of 10-20 mm, after which the value of the load remained unchanged. The pull-out tests showed that the existence of steel fibers improved the pull-out resistance of strands by controlling the crack growth inside concrete blocks. This way, the level of confinement at the strandconcrete interface was increased, which resulted in improvements in both the friction and mechanical bond components of the resistance. Such behavior is evident by the fact that the average measured pull-out strength of SFRC specimens are all larger than that of the corresponding plain concrete specimens.
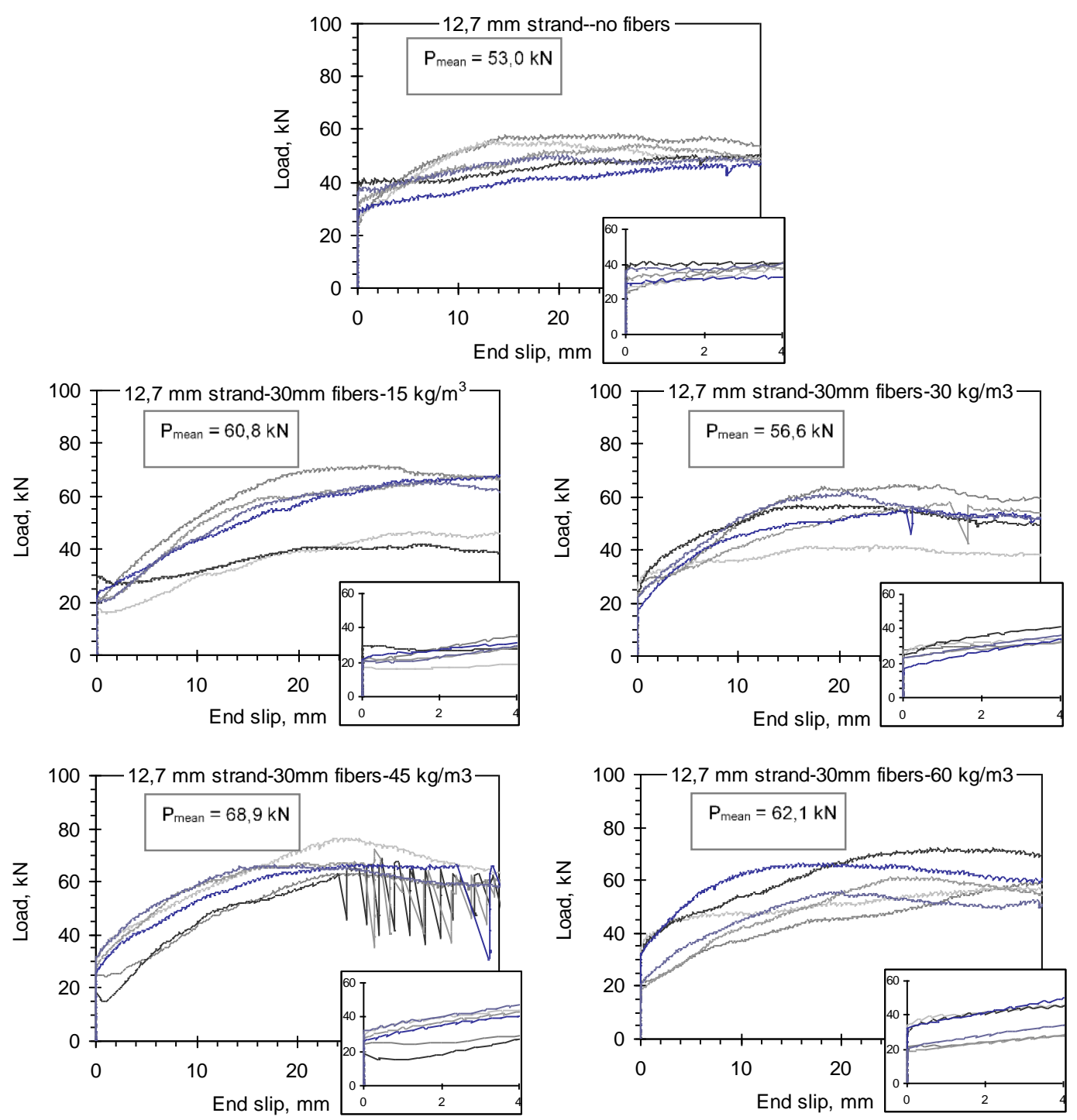

Figure 4. Pull-Out Behavior of Strands 
Beam Tests. Even though the flexural behavior of SFRC beams has been the subject of many research studies, reinforced concrete beams with a fixed amount of longitudinal reinforcement was used in majority of these studies. However, the flexural response of a reinforced concrete beam in terms of the failure mode and ductility depends heavily on the amount of longitudinal reinforcement present in the member. Therefore, there is a need to evaluate the behavior of reinforced concrete beams with SFRC for various longitudinal reinforcement amounts covering the whole range of flexural behavior. In order to address this need, flexural behavior of reinforced concrete beams with SFRC was investigated with increasing amount of reinforcement. The overall goal was to identify the difference in mechanisms through which the existence of steel fibers improves the flexural response of lightly and relatively heavily reinforced concrete beams.

Table 3. Details of Beam Specimens

\begin{tabular}{|c|c|c|c|c|c|}
\hline Specimen & Concrete Type* & Bar Diameter $(\mathrm{mm})$ & Number of Bars & Reinf. Area $\left(\mathrm{mm}^{2}\right)$ & Reinf. Ratio (\%) \\
\hline CC- 0.20 & $\mathrm{CC}$ & \multirow{2}{*}{10} & \multirow{2}{*}{1} & \multirow{2}{*}{78.5} & \multirow{2}{*}{0.20} \\
\hline SFRC-0.20 & SFRC & & & & \\
\hline CC- 0.30 & $\mathrm{CC}$ & \multirow{2}{*}{12} & \multirow{2}{*}{1} & \multirow{2}{*}{113.1} & \multirow{2}{*}{0.30} \\
\hline SFRC- 0.30 & SFRC & & & & \\
\hline CC- 0.40 & $\mathrm{CC}$ & \multirow{2}{*}{14} & \multirow{2}{*}{1} & \multirow{2}{*}{153.9} & \multirow{2}{*}{0.40} \\
\hline SFRC- 0.40 & SFRC & & & & \\
\hline CC- 0.53 & $\mathrm{CC}$ & \multirow{2}{*}{16} & \multirow{2}{*}{1} & \multirow{2}{*}{201.1} & \multirow{2}{*}{0.53} \\
\hline SFRC- 0.53 & SFRC & & & & \\
\hline CC- 0.81 & $\mathrm{CC}$ & \multirow{2}{*}{14} & \multirow{2}{*}{2} & \multirow{2}{*}{307.9} & \multirow{2}{*}{0.81} \\
\hline SFRC-0.81 & SFRC & & & & \\
\hline CC-1.06 & $\mathrm{CC}$ & \multirow{2}{*}{16} & \multirow{2}{*}{2} & \multirow{2}{*}{402.1} & \multirow{2}{*}{1.06} \\
\hline SFRC-1.06 & SFRC & & & & \\
\hline CC-1.60 & $\mathrm{CC}$ & \multirow{2}{*}{16} & \multirow{2}{*}{3} & \multirow{2}{*}{603.2} & \multirow{2}{*}{1.60} \\
\hline SFRC1.60 & SFRC & & & & \\
\hline
\end{tabular}

*SFRC: steel fiber reinforced concrete; CC: conventional concrete
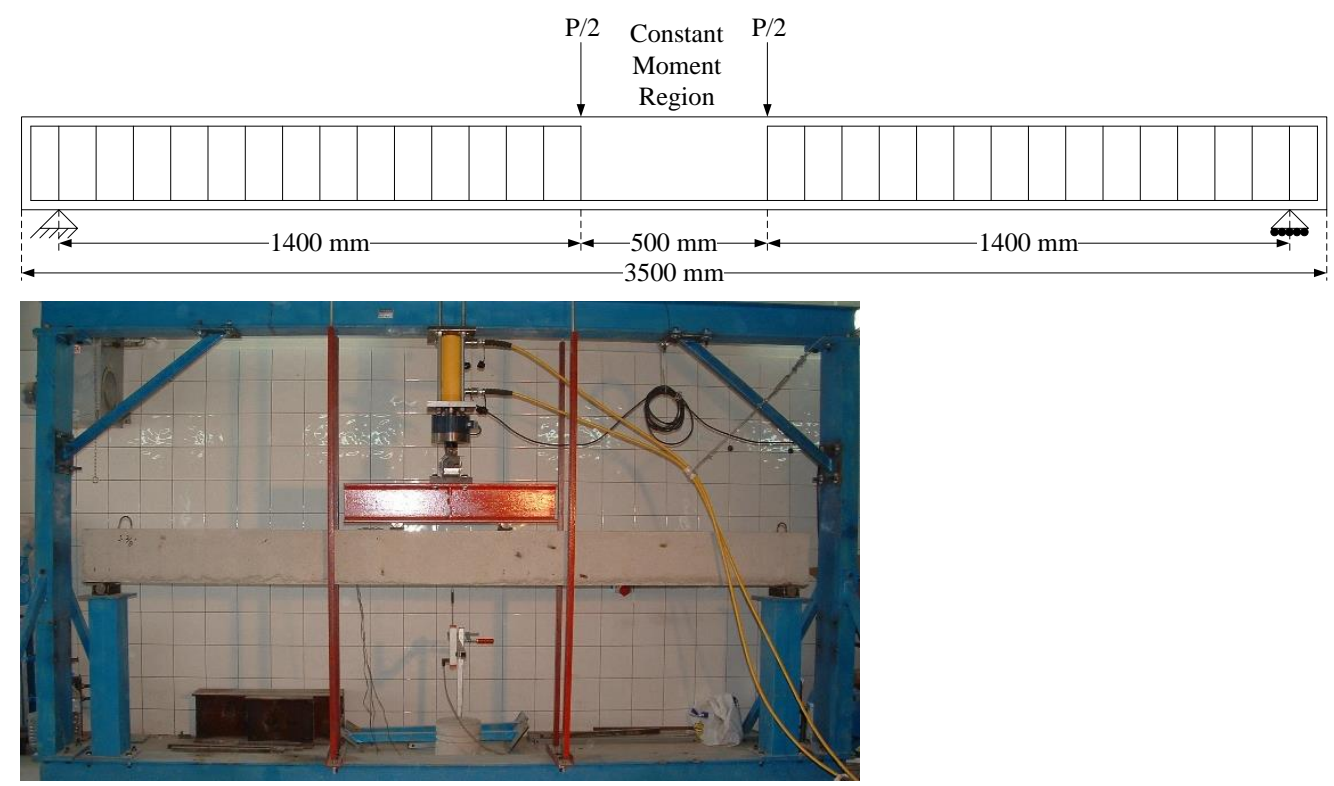

Figure 5. Details of Beam Specimens and Test Setup 
Load tests were conducted on fourteen reinforced concrete beams having $180 \times 250 \mathrm{~mm}$ rectangular cross section and $3300 \mathrm{~mm}$ span length. The main parameters in the testing program were the type of concrete (CC and SFRC) and the amount of longitudinal reinforcement. Seven different longitudinal reinforcement ratios, ranging from $0.2 \%$ to $1.60 \%$ were used in the testing program. Two specimens were cast for each longitudinal reinforcement ratio, one specimen with CC and another specimen with SFRC. Details of the test specimens are presented in Table 3. Dramix ZP-305 hooked end steel fibers with 1\% fiber content was used in the SFRC specimens. Two-point loading was applied on the specimens as indicated in Figure 5. Monotonically increasing displacement loading was applied on specimens and the total load applied by the hydraulic jack was measured with a load cell. A load spreader beam was used to distribute the total load at two loading points so that a constant moment region of $500 \mathrm{~mm}$ length was obtained. Vertical displacement at the midspan of beams was measured and recorded continuously during load tests.

Results of Beam Tests. All beams developed vertical flexural cracks mainly around constant moment region prior to crushing of concrete near the top part of the cross section. The beams suffered damage by gradual development of multiple cracks with increasing deflection, but retained their structural integrity and post-peak resistance even with considerable deflection. The crack initiation load of conventional concrete beams was similar to those of the SFRC beams. A sudden crushing of concrete was observed in the conventional concrete beams with few larger cracks prior to crushing, as opposed to the gradual crushing of concrete observed in the SFRC beams.

Load versus midspan deflection response of the CC and SFRC series beams are given in Figure 6. As evident in the load-deflection plots, the existence of steel fibers influenced the flexural behavior of the reinforced concrete beams in completely different ways depending on the amount of longitudinal reinforcement present. For lightly reinforced concrete beams, addition of steel fibers slightly increased the bending moment capacity with a significant reduction in the deformation capacity. In specimens SFRC0.20 , SFRC-0.30, and SFRC-0.40 the failure was due to fracture of the longitudinal reinforcement. On their counterparts with conventional concrete, however, no such fracture was observed, and the failure occurred due to crushing of concrete at the top surface within the constant moment region. For the relatively heavily reinforced concrete beams, on the other hand, the steel fibers significantly improved the ductility by increasing the midspan deflection at which failure occurred. The experimentally determined load capacity and midspan deflection values are tabulated in Table 4.

Table 4. Comparison of Beam Response with and without Steel Fibers

\begin{tabular}{|c|c|c|c|c|c|c|}
\hline \multirow{2}{*}{$\begin{array}{c}\text { Reinf. } \\
\text { Ratio (\%) }\end{array}$} & \multicolumn{2}{|c|}{ Ultimate Load (kN) } & \multicolumn{2}{c|}{$\begin{array}{c}\text { Ultimate Deflection } \\
(\mathrm{mm})\end{array}$} & \multicolumn{2}{c|}{$\begin{array}{c}\text { Service Stiffness } \\
(\mathrm{kN} / \mathrm{mm})\end{array}$} \\
\cline { 2 - 7 } & CC & SFRC & CC & SFRC & CC & SFRC \\
\hline \hline 0.20 & 11.8 & 18.7 & 111 & 65 & 1.28 & 1.50 \\
\hline 0.30 & 18.5 & 21.3 & 110 & 86 & 1.19 & 1.43 \\
\hline 0.40 & 25.4 & 27.5 & 108 & 95 & 1.28 & 1.60 \\
\hline 0.53 & 31.6 & 34.9 & 104 & 157 & 1.82 & 2.11 \\
\hline 0.81 & 47.9 & 47.0 & 92 & 177 & 1.96 & 2.21 \\
\hline 1.06 & 58.1 & 61.8 & 57 & 176 & 2.62 & 2.88 \\
\hline 1.60 & 81.4 & 82.4 & 42 & 164 & 3.42 & 3.75 \\
\hline
\end{tabular}

The service stiffness for each specimen was obtained as the slope of the load-deflection curve between the points corresponding to the $50 \%$ and $80 \%$ of the ultimate load. This region of load-deflection curves of the specimens corresponds to "cracked section" behavior. The stiffness computed this way is called as the "service stiffness" mainly because under realistic service loads the behavior of properly designed reinforced concrete beams will be in the cracked state and prior to yielding of reinforcement. A comparison of the 
service stiffness values given in Table 4 indicates that for all reinforcement ratios, the SFRC beams had larger service stiffness than their counterparts with conventional concrete.
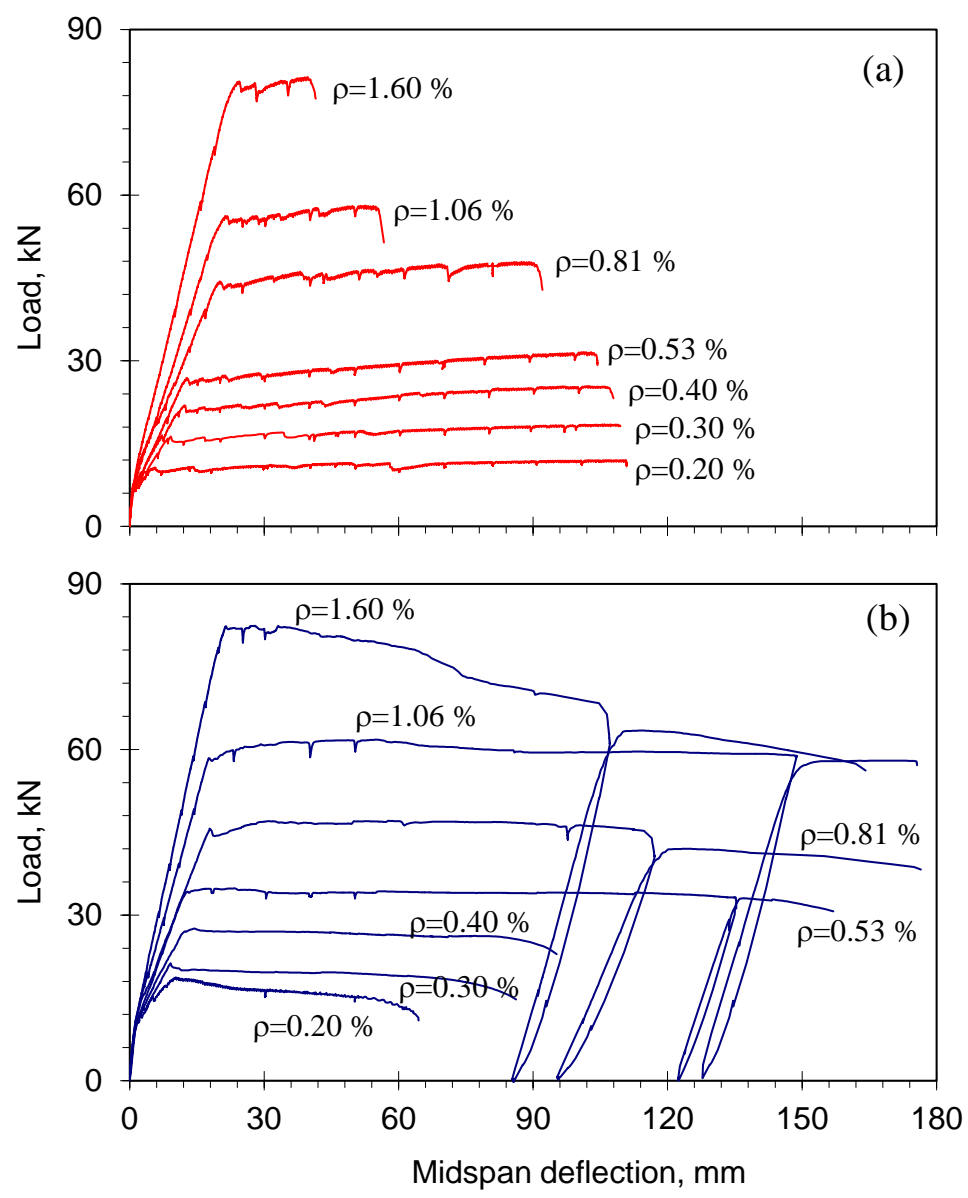

\section{Figure 6. Load-Deflection Response of Beam Specimens: (a) CC Beams; (b) SFRC Beams CONCLUSION}

This paper presents examples of how the addition of steel fibers improves the mechanical performance in two different concrete applications: (1) bond behavior of prestressing strands and (2) flexural behavior of reinforced concrete beams. The following conclusions can be drawn based on the experimental findings:

- Prestressing strands resist the pull-out loads through a mechanism that is a combination of friction and mechanical bond between strands and the surrounding concrete. The latter of these mechanisms occur when there is a restraint against the free rotation of strands.

- The overall shape of the pull-out load versus strand slip curves is not influenced by fiber content. The shape of such curves for strands embedded in plain concrete may depend on the size of the specimens tested. Small specimens may suffer from excessively wide cracks and concrete splitting, which causes the pull-out load versus strand slip plot to drop rapidly.

- Steel fibers improve the pull-out resistance of strands by controlling the crack growth inside concrete blocks. This way, the level of confinement at the strand-concrete interface is increased, which results in improvements in both the friction and mechanical bond components of the resistance. The results 
indicate that more than $15 \%$ increase in pull-out strength is possible with fiber contents as low as 15 $\mathrm{kg} / \mathrm{m}^{3}$.

- For lightly reinforced concrete beams, addition of steel fibers slightly increased the bending moment capacity with a significant reduction in the deformation capacity. For heavily reinforced beams, on the other hand, the steel fibers significantly improved the ductility with no significant change in moment capacity.

- For all reinforcement ratios studied, the presence of steel fibers resulted in an increase of $10 \%-25 \%$ in service stiffness of reinforced concrete beams.

- Steel fiber reinforced concrete offers a strong potential for a more sustainable and more economical alternative to conventional concrete. Use of steel fibers in concrete members also results in improved mechanical performance.

\section{REFERENCES}

ASTM C1018. (1997). "Standard Test Method for Flexural Toughness and First-Crack Strength of FiberReinforced Concrete." ASTM International, West Conshohocken, PA.

Abdul-Ahad, R. B. and Aziz, O. Q. (1999). "Flexural Strength of Reinforced Concrete T-Beams with Steel Fibers." Cement \& Concrete Composites, 21, 263-268.

Altun, F., Haktanir, T., and Ari, K. (2007). "Effects of Steel Fiber Addition on Mechanical Properties of Concrete and RC Beams." Construction and Building Materials, 21, 654-661.

Ashour, S. A., Wafa, F. F., and Kamal, M. I. (2000). "Effect of the Concrete Compressive Strength and Tensile Reinforcement Ratio on the Flexural Behavior of Fibrous Concrete Beams." Engineering Structures, 22(9), 1145-1158.

Chao, S., Naaman, A., Parra-Montesino, G. (2006). "Bond behavior of strand embedded in fiber reinforced cementitious composites." PCI Journal, 51(6), 56-71.

Dancygier, A. N. and Savir, Z. (2006). "Flexural Behavior of HSFRC with Low Reinforcement Ratios." Engineering Structures, 28, 1503-1512.

Elliot, K. S., Peaston, C. H., and Paine, K. A. (2002). "Experimental and Theoretical Investigation of the Shear Resistance of Steel Fibre Reinforced Prestressed Concrete X-Beams - Part II: Theoretical Analysis and Comparison with Experiments." Materials and Structures, 35 (9), 528-535.

Girgis, A.F.M., Tuan, C.Y. (2005). "Bond Strength and Transfer Length of Pretensioned Bridge Girders Cast with Self-Consolidating Concrete.” PCI Journal, 50(6), 72-87

Gustavo, J. P., James, K. W., and Hai, H. D. (2010). "Shear Behavior of Steel-Fiber Reinforced Concrete Beams without Stirrup Reinforcement." ACI Structural Journal, 107(5), 576-606.

Logan, D.R. (1996). "Discussion of a Review for Strand Development Length for Pretensioned Concrete Members." PCI Journal, 41(2), 112-116.

Olivito, R. S. and Zuccarello, F. A. (2010). "An Experimental Study on the Tensile Strength of Steel Fiber Reinforced Concrete." Composites Part B: Engineering, 41(3), 246-255.

Padmarajaiah, S. K. and Ramaswamy, A. (2004). "Flexural Strength Predictions of Steel Fiber Reinforced High-Strength Concrete in Fully/Partially Prestressed Beam Specimens." Cement and Concrete Composites, 26(4), 275-290.

Qian, C. and Patnaikuni, I. (1999). "Properties of High-Strength Steel Fiber-Reinforced Concrete Beams in Bending." Cement \& Concrete Composites, 21, 73-81.

Rose, D.R. and Russel, B.W. (1997). "Investigation of Standardized Tests to Measure the Bond Performance of Prestressing Strand.” PCI Journal, 42(4), 56-80. 